employed it in cases in which its use was clearly indicated.

Let it not be thought that $I$ desire to vaunt the lobelia, and extol its virtues above its merits, nor to palm it upon the world as a charm or a specific. No! but as a powerful and valuable auxiliary for the relief of disease and the amelioration of human suffering.

It shonld not be imagined, from the above remarks, that its employment is to supersede every other remedy, - the use of the lancet, mercury, antimony, \&c. \&c., but its grand effect is to obtain repose in those cases of pulmonary or thoracic disease where the chief object is to quiet and relieve the painful efforts at respiration.

There are many cases, I am well aware, which we meet with in children, sometimes in adults, where the respiratory passages are so clogged by excessive secretion, arising from some morbid state of the tissues themselves, and kept up primarily by the debility of the capillaries, and secondarily by the general atony of the system, where a permanent benefit can only be anticipated by the exhibition of tonics, \&c.; and here comes in the judgment and discrimination of the practitioner to determine the important point of treatment, Shall he give quinine or iron where there is troublesome cough and much dyspnoea?

The careful examination of the patient, both constitutionally and locally, his aspect, general health, temperament, physical appearances, \&c. \&cc.; the exploration of the chest by a careful stethoscopic examination, must be his guides, and safe ones, too, will he find them. Next comes the query,May not the sedutive and the tonic be happily blended?

The results which spring from such a combination are very pleasing to the medical man, and most grateful to his patient; whilst the sedative induces repose and quiets the urgent efforts at inspiration, the part recovers tone by the influence of the said repose; and the action of the tonic upon the capillary system prohibits the secretion of more; the resained power, both by the tonic and the sedative, enables the parts to throw of the excessive secretion, and the general health is improved and the disease disappears.

I have given the lobelia, also, in some diseases of the heart with great benefit, in pleurisy, \&c. \&c.; but I reserve whatever observations I may make upon these subjects for a future communication.

It only remains for me, now, to mention the preparation of the lobelia which I employ; it is the ethereal tincture, made with the compound sulphuric ether; and this forms the best preparation, the most active, of the lobelia. There is a tincture made with the nitric ether, but that is a preparatios far inferior to the sulphuric; I obtain it at Apothecaries' Hall, being particular to obtain the comp. sulph. tinct.; it is of a greenish-yellow tint; the dose I commence with, from 10 to 15 minims, generally the former, to be repeated every one, two, or three hours, until relief is obtained.

If I have occupied too much space I can only solicit the indulgence of the reader. My earnest desire that the great value of the lobelia should be generally known has, perhaps, made me rather prolix.

\section{UNEXPECTED PTYALISM.}

\section{To the Editor of The Lancet.}

SIR :-I am induced to transmit to you, for publication, if you deem it sufficiently interesting, the following case of ptyalism, arising from the accidental, if $I$ may use the term, exhibition of minute doses of calomel, and the treatment adopted, in order to meet the wishes of $\mathrm{Mr}$. Potter, conveyed in the last Number of The Lancet. As a junior practitioner my experience in similar cases has not been extensive, but the same successful results having invariably followed, they confirm, in my mind, the propriety of the course pursued, and I venture, with great deference, to submit the practice to the notice of the profession. I am, Sir, your faithful servant,

\section{Egham, Nov. 3, 1838.}

\section{G. P. Heyward.}

Sept. 26, 1837. J. W., ætat. 58, requested me to send him a box of aperient pills, and I prescribed as follows:-

Calomel, 12 grains ;

Comp. extract of colocynth, 1 drachm. Divide into 12 pills; one or two, according to circumstances.

Oct. 5. His bowels having become constipated, he had recourse to the pills, and during 48 hours he took eight of them, containing, of course, eight grains of calomel, and two scruples of the compound extract of colocynth, without obtaining an evacuation. At this period $I$ was sent for, and his constitution was evidently under the influence of the mercury; his head, face, and tongue, were swollen, and salivation had commenced; the breath was very offensive; tongue furred; pulse full.

Sulphate of magnesia, 1 ounce ;

Croton oil, 2 drops ;

Comp. infus. of senna, $\frac{1}{2}$ ounce ;

Tincture of senna, 2 drachms. One quarter part to be taken at once, and repeated every two hours, until purgation follows.

6. The bowels have been freely purged; the evacuations are dark and extremely foe. tid; the swelling of the head and face has increased; tongue moist; pulse regular; the salivation is more abundant. 
Subcarb. of soda, 1 drachm;

Camphor mixture, 5 ounces;

Tinct. of ipecac., 1 drachm;

Comp. spirit of ammonia, $1 \mathrm{drachm}$. fourth part every six hours.

Alum, 1 drachm;

Co. infus. of roses, $1 \frac{1}{2}$ ounces; gargle.

Tinct. of myrrh, $\frac{1}{2}$ ounce. Make

His diet to consist of milk principally, va. ried with an occasional light pudding, or arrow-root, sago, and his ordinary drink, toast and water, flavoured with a tablespoonful of brandy to each tumbler.

7. Salivation increased; otherwise the same as yesterday. Continue medicines; a dose of castor oil to relieve the bowels.

8. His features are now so swollen that he can scarcely be recognised by his friends; the salivation is profuse; his breath very offensive; the bowels and pulse regular; complains of thirst; perspires freely in bed. Ordered warm fomentations to the head and face. Continue mixture. His tongue is so much enlarged that he cannot use the gargle.

Borate of soda, two drachms, to be mixed with honey and applied to the mouth.

This treatment was pursued, with progressive improvement, until the $16 \mathrm{th}$, when the swelling of the head and face, and all the more prominent symptoms subsided. Previous to his application to me he had been afficted, for years, with dyspepsia of a severe character, accompanied with painful vomiting every morning after quitting his bed. He had sought the advice of various practitioners without obtaining permanent relief, and naturally felt reluctant to confide himself to my care, believing his case to be hopeless, and admitting of slight palliation only. I may here state that $I$ availed myself of the opportunity so unexpectedly afforded me, to combat the primary affection, and that, by the administration of appropriate remedies, a cure was effected, probably accelerated by the salivation; he is now in better health than he has been for years.

\section{INJECTION OF DEAD BODIES.}

To the Editor of The LANCET.

SrR :-I beg leave to send for insertion, in your widely-circulating periodical, an outline of an instrument which $I$ have invented for the purpose of facilitating the injection of the dead subject, through a medio-vertical section of the sternum. By the employment of the usual means considerable difficulty is met with in separating the segments of the bone far enough to admit of the injecting pipe being secured in the vessel, with the certainty of ensuring a free injection, without extravasion of the fluid into the thorax. This difficulty is completely obviated by the instrument. On IV onday last I had an opportumity of trying its power on a fine muscular male subject, in the dissecting-room of the Westminster School of Medicine, through the kindness of one of the lecturers, Mr. Savage, to whom, indeed, Iam indebted for many valuable suggestions, whilst manufacturing his instruments for the dissecting-room.

The two plates, closely approximated, were inserted into the fissure left by the

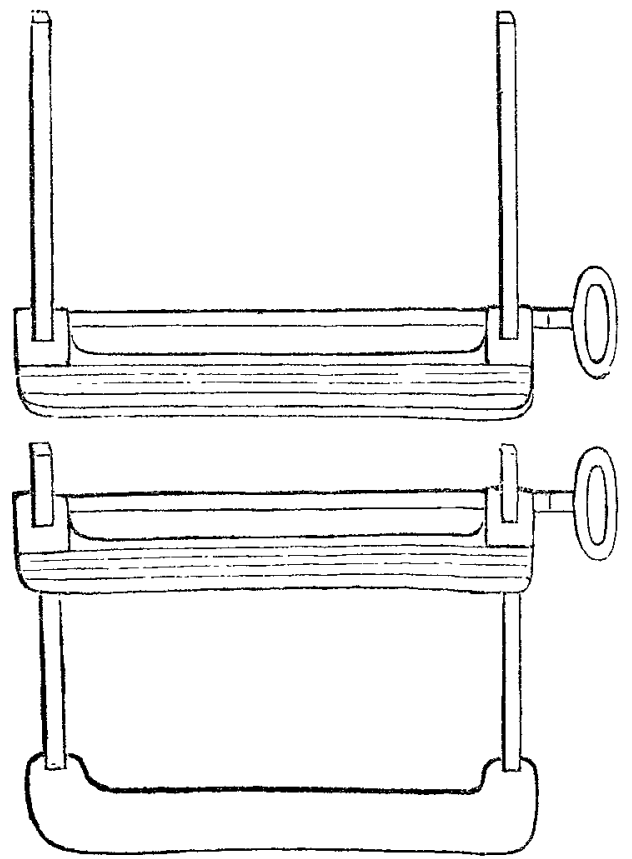

saw; a few turns of the handle sufficed to dilate it to the extent of six inches, withont the slightest disturbance of the thoracic viscera. Begging the favour of an early insertion I remain, Sir, your obedient servant,

35 Charles-street, Middlesex Hospital, Nov. 12, 1838.

\section{MONSTROUS FEMALE FETUS.}

\section{To the Editor of THE LANCET.}

SIR:-Should you deem the drawings I have made and forwarded to you, of a child which was born on the 23rd instant, worthy of insertion in the pages of your Journal, I freely present them for your adoption.

I remember, during my articleship with Mr. Higginbottom, of Nottingham, a simi. lar production being shown me; but the malformation of the spine was not carried to near the extent, nor had the child arrived at half the age of the one now shown in the engraving. The preparation is now in the possession of Dr. Taylor, St. Paul'ssquare. I have the honour to be, Sir, your very obedient servant,

W. Andrew, Surgeon, \&c,

Liverpool, Oet. $31,1838$. 